\title{
FORNIR LOS CASTELLS E VILA DE MURVEDRE. LAS OBRAS Y EL APROVISIONAMIENTO DEL CASTILLO DE MORVEDRE DURANTE LA GUERRA DE CASTILLA (1365-1366)
}

\author{
FORNIR LOS CASTELLS E VILA DE MURVEDRE. THE WORKS AND THE SUPPLY OF THE \\ CASTLE OF MORVEDRE DURING THE WAR OF CASTILE (1365-1366)
}

POR

Miquel Faus Faus*

\section{RESUMEN - ABSTRACT}

Los castillos eran la espina dorsal del sistema defensivo del reino de Valencia, así como de todos los estados feudales. A través del análisis de la contabilidad de un libro de obras relativo al castillo de Sagunt analizamos el papel de los castillos valencianos en la defensa del territorio y su importancia en la creación de tejido económico y en la movilización de mano de obra. El volumen es especialmente interesante porque también refleja el abastecimiento alimentario y la compra de armamento. Además, las cuentas analizadas se realizaron durante la Guerra de Castilla (1356-1375) uno de los momentos claves de la historia de la Corona de Aragón.

The castles were the backbone of the defensive system of the Kingdom of Valencia, as well as of all the feudal states. Through the analysis of an account book of construction works from the castle of Sagunt we analyze the role of the Valencian castles in the defense of the territory and its importance in the creation of an economic fabric and in the mobilization of labor. The volume is especially interesting because it also reflects the food supply and the purchase of weapons. In addition, the accounts analyzed were carried out during the War of Castile (1356-1375) one of the key moments in the history of the Crown of Aragon.

\section{Palabras Clave - Keywords}

Castillos; obras; Guerra de Castilla; abastecimiento alimenticio; compra de armamento; Sagunt.

Castles; construction work; War of Castille; food supply; arms purchases; Sagunt.

\section{Cómo CITAR ESTE ARTículo / CitATion}

Faus Faus, M. (2021): «Fornir los castells e vila de Murvedre. Las obras y el aprovisionamiento del castillo de Morvedre durante la guerra de Castilla (1365-1366)». Gladius, 41: 137-151. https://doi.org/10.3989/gladius.2021.08

RECIBIDO / RECEIVED: 24-04-2019

ACEPTADO / ACCEPTED: 16-06-2020

* Investigador Predoctoral Contratado (Contrato FPU del Ministerio de Ciencia, Innovación y Universidades), Departament d'Historia Medieval i Ciències i Tècniques Historiogràfiques, Universitat de València, miquel.faus@uv.es / ORCID iD: https:// orcid.org/0000-0001-5725-8377 


\section{INTRODUCCIÓN}

La guerra en la Edad Media tuvo a los castillos como uno de sus protagonistas principales. Esto hizo que los conflictos se movieran por estrategias que versaban alrededor de posiciones defensivas distribuidas por el territorio. El reino de Valencia había heredado una red de fortificaciones andalusíes que fueron el fundamento del sistema defensivo feudal. De entre todos los castillos del territorio valenciano, el de Morvedre, actual Sagunt, es probablemente uno de los que han tenido una mayor importancia estratégica desde las guerras púnicas hasta las guerras napoleónicas. Esta fortaleza ha custodiado el paso natural del interior hacia el litoral y desde la capital valenciana hacia las tierras catalanas.

A partir de un libro de contabilidad de las obras de este castillo se pueden reconstruir algunos de los aspectos fundamentales del estado, el abastecimiento y el papel que desempeñaban las fortalezas valencianas en tiempo de paz y en tiempo de conflicto. El cuaderno además se redactó en uno de los períodos más intensos y conflictivos de la historia del reino de Valencia: la Guerra de Castilla (1356-1375).

\section{LA GUERRA CON CASTILLA}

Desde su fundación en el siglo XIII hasta su desaparición con la Nueva Planta borbónica de 1707, no hubo un conflicto bélico tan devastador para el reino de Valencia como el de la Guerra de Castilla (1356-1375). La contienda enfrentó a Pedro I el Cruel, rey de Castilla, con Pedro IV el Ceremonioso, monarca de la Corona de Aragón. En esta larga guerra se vieron implicados, de mayor o menor forma, todos los territorios ibéricos, pero fue en el escenario valenciano donde probablemente el enfrentamiento causó más estragos: asesinatos, pérdida de cosechas, robo de ganado, destrucción de campos y estructuras hidráulicas... Esta contienda, más que la peste, fue el mayor destructor del tejido económico para las comunidades locales (Furió, 2001: 114-116). La situación amenazó con destruir la misma entidad política del reino de Valencia, tal y como se indica en un fragmento de la Crónica de Pedro el Ceremonioso: «E el dit rei havia posat nom e títol a tota la terra que ens havia tolta, així en regne d'Aragó com en regne de València, Castella la Nova, mas, per la gràcia de nostre Senyor Déus, lo dit títol durà poc» ${ }^{1}$. Por otra parte, la difícil coyuntura transformó la configuración de los ejércitos reales aragoneses y especialmente la fiscalidad, introduciendo ciertas dinámicas (como la implantación de las generalidades, los impuestos extraordinarios o la emisión de deuda pública) que caracterizaran los cambios económicos de la Corona en las siguientes décadas (Lafuente, 2014: 345-354)

La primera etapa de la guerra (1356-1361) ha sido descrita por el doctor Mario Lafuente como un periodo de equilibrio de fuerzas entre ambos bandos. Estos primeros años estuvieron marcados por momentos de tregua alternados con otros de beligerancia en los que el rey castellano se dedicó a ocupar algún castillo o villa valenciana, mientras mantenía una política constante de incursiones y saqueos en los territorios fronterizos (Lafuente, 2012: 55-94). Fue sin duda la segunda fase (1362-1366) la que supuso un mayor trauma al reino porque se saldó con la ocupación de numerosas plazas valencianas. En la primera ofensiva castellana en junio de 1362 se ocuparon Castielfabib, Ademuz, Jérica, Segorbe, Almenara, El Puig, Llíria, Benaguasil, Xiva, Bunyol y Macastre. No obstante, la mayor victoria castellana fue la ocupación de la villa y castillo de Morvedre en el corazón del reino de Valencia, pues, con esta victoria, se aseguraba una base de operaciones entre las vías naturales de comunicación entre la ciudad de Valencia y Aragón, Cataluña y el norte del reino. Desde aquí se coordinó en mayo de 1363 un asedio a la ciudad de Valencia. En diciembre del mismo año cayeron en manos castellanas algunas plazas del sur del país (Alacant, Elx, Asp, Xixona...) o del litoral (Dénia, Oliva, Gandía, Cullera...). Estas nuevas conquistas llevaron a un segundo asedio a la ciudad de Valencia en marzo de 1364. Pero esta vez el rey Pedro el Ceremonioso se desplazó con su ejército para ayudar a los de la Capital a lo cual el monarca castellano contestó evitando el enfrentamiento en campo abierto y refugiándose en Morvedre (Belenguer, 2015: 157 187; Lafuente, 2012: 95-117).

En febrero de 1365 el rey aragonés tomaba la iniciativa y se lanzaba a asediar Morvedre, baluarte de la presencia castellana en el territorio valenciano. La villa aguantó seis meses de cerco y de constante bombardeo de maquinaria de asedio

${ }^{1}$ Extraído de la Crònica de Pere III el Cerimoniós edición de Ferran Soldevila (2014), Barcelona, Institut d'Estudis Catalans, 394. 
hasta que finalmente la guarnición castellana se rindió el 14 de septiembre de $1365^{2}$. La universidad pagó cara su participación y colaboración con los castellanos en la guerra. Según muestran los capítulos de la composición entre el rey aragonés y la villa, una vez tomada la plaza, esta última pasaba a incluirse dentro del término general de Valencia y se convertía en una calle más dentro de la misma ${ }^{3}$. La recuperación del enclave inició un proceso de victorias aragonesas que consiguieron alejar el frente de la capital del reino y asegurar Segorbe y el valle del Palancia. Pedro el Ceremonioso aprendió con grandes pérdidas la importancia estratégica de Morvedre y tomó medidas para asegurar que el castillo y la villa no volviesen a caer en manos castellanas.

\section{LA GESTIÓN DE UN CASTILLO DURANTE LA GUERRA}

Asegurar el castillo de Sagunto y evitar que no volviese a estar en control de las tropas del rey Pedro el Cruel requería de la conjunción de cuatro factores: en primer lugar, de la reparación y el refuerzo de las estructuras defensivas con las que contaba la villa; en segundo lugar, del aprovisionamiento de víveres y el mantenimiento de aljibes para garantizar la supervivencia de la población y las tropas allí instaladas; en tercer lugar de abastecer de armamento para defender la posición en caso de ataque; y, finalmente, de situar una guarnición al cargo de la defensa de la plaza. De las tropas estacionadas en el Castillo de Morvedre tras su recuperación nos hablan tres entradas de la tesorería real de Pedro el Ceremonioso. Este había apostado el 30 de septiembre a 92 hombres, entre lanceros y ballesteros, durante trece días, los cuales percibían 1989 sueldos de soldada. Acabado este período de tiempo, la nómina de tropas se reducía a 69 por otros 13 días. Además, el 6 de octubre, se contrataban otros 21 almogávares por 304 sueldos por un tiempo desconocido ${ }^{4}$. De este momento en adelante no tenemos más noticias de tropas pagadas por el rey, lo cual no impide que no hubiese tropas mantenidas por Morvedre, por la ciudad de Valencia o por otra entidad. Tampoco podemos descartar que con el retroceso del frente

\footnotetext{
2 ACA, Real Cancillería, 1206, f. 81v-93r.

3 ACA, Real Cancillería, 1216, f. 106r-108v.

4 ACA, Mestre Racional, 352, f. 97v-98r.
}

castellano el monarca aragonés decidiese desplazar este contingente hacia otros puntos más necesarios.

Para la gestión de los otros factores necesarios para la fortaleza el monarca nombró comisario a Francesc de Vic, ciudadano de Valencia, según se indica, para «fornir los castells e vila de Murvedre, çò es, saber d'armes, areneses, viandes e altres coses que fossen necessàries»». Francesc de Vic atendía estos asuntos, tradicionalmente asociados el alcaide del castillo (Ferrer i Mallol, 1990: 177-189), y, durante los diez meses en los que los dirigió, llevó una meticulosa contabilidad recogida en un libro que debía llevar al mestre racional para su posterior auditoría. Este libro que conservamos y ha sido base para nuestro estudio, ${ }^{5}$ muestra un desglose minucioso y pormenorizado de todos los gastos realizados durante diez meses en los trabajos del castillo.

Un análisis de este volumen de cuentas nos da un gasto total de 63800 sueldos y 6 dineros. Según podemos observar (Fig. 1), 23093 sueldos y 8 dineros, la mayor parte de los gastos (36\%), se dedicaban al abastecimiento de alimentos, seguido de cerca por el gasto en salarios (32\%) que se sitúa en 20088 sueldos y 7 dineros. En una tercera posición encontramos el gasto en armamento (17 \%) que se calcula en 10805 sueldos y 6 dineros. Finalmente está el gasto en materiales que llega a los 10805 alrededor de un $15 \%$ del gasto, entre los que también hemos incluido las compras de componentes de molinos, baños...

\section{LA RECONSTRUCCIÓN DE MORVEDRE}

\subsection{Las Obras}

La imagen de la villa y el castillo en el momento de la entrada de las tropas aragonesas el 14 de septiembre de 1365 debió ser desoladora. Por una parte, defensores fatigados por el combate y el hambre. Por otra, la villa se encontraría muy dañada después de seis meses de bombardeo. El 17 del mismo mes empezaron las obras de reconstrucción que tenían como objetivo fortificar la posición, pero también reconstruir los edificios pertenecientes al realengo para poder garantizar su rápida vuelta al funcionamiento. Algunas de

\footnotetext{
${ }^{5}$ Referencia de archivo ACA, Mestre Racional, 2433.
} 


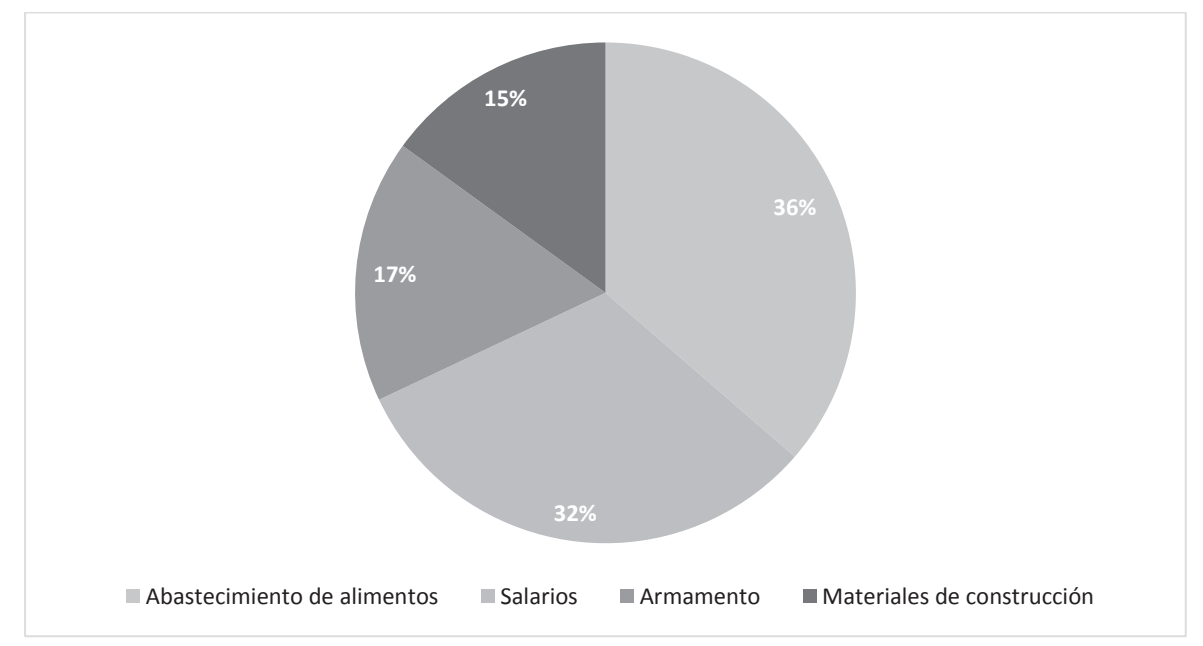

Figura 1. Porcentaje de gastos dedicados a la reconstrucción y el abastecimiento del castillo de Morvedre.

las principales obras que se llevaron a cabo en las dichas propiedades reales fueron:

- En el almudín, retirar los escombros que había causado el derrumbe del techo al sucumbir este al fuego de los trabucos de Pedro el Ceremonioso, así como reconstruir sus puertas y su cubierta con cañas y tejas.

- En los baños, remediar los destrozos causados por los castellanos y por los "ginys" de los aragoneses, así como reconstruir la "cadufada" o la tubería de caños de cerámica que abastecía de agua el baño.

- En los molinos tenemos constancia de que se trabajó en al menos cuatro molinos diferentes dos hidráulicos y dos "de la sang" o de tracción animal. Según hemos podido identificar los dos molinos hidráulicos, llamados de Bonafont de Sant Feliu y de Ponç Armengol, estaban situados en la villa y entre las obras más importantes que se realizaron en ellas estaban la limpieza de las acequias que los abastecían y la reparación de sus partes. Por el contrario, los de tracción animal se situaban en el castillo y de ellos solo tenemos información de cambios de piezas (especialmente muelas y lorigas) y alguna reparación menor con yeso.

Pero aquello que nos interesa ahora son las obras de carácter defensivo realizadas en el castillo y en las murallas con el objetivo de convertir Morvedre en un bastión inexpugnable. La fortale- za cristiana se levanta sobre un hisn andalusí, a su vez levantado sobre edificaciones iberas y romanas, del cual aún conserva la morfología general. A pesar de no existir ningún trabajo exhaustivo al respecto, los expertos coinciden en la identificación de los principales recintos: Albacar, Almenara, Saluquía y Albarranía (Fig. 2). Sin embargo, las transformaciones que sufrió el conjunto hasta el siglo XIX y la falta de más estudios arqueológicos sigue impidiéndonos reconocer posibles estructuras del siglo XIV ${ }^{6}$.

Desconocemos cuál era el estado del castillo antes del inicio de la guerra, pero sería descabellado pensar que fuera deficiente. La ya citada profesora María Teresa Ferrer i Mallol demostró en su momento que los castillos de la Gobernación de Orihuela tenían un estado precario, tanto por lo que respecta a las mismas estructuras de los edificios, como por sus menguadas guarniciones y reservas que no llegaban a cumplir los estándares de mantenimiento por los que recibían unos ingresos anuales (Ferrer i Mallol, 1990: 177-189). Esta precariedad del sistema castral del sur del reino de Valencia parece coincidir con la de los castillos de

${ }^{6}$ La mayor parte de los estudios sobre la arquitectura medieval de Morvedre se basan en el estudio de Basilio Pavón, 1978. En lo que se refiere al castillo el autor fundamenta su trabajo en la observación de los restos y en otros estudios de la primera mitad del siglo XX, pero no en documentación de archivo ni en partes de excavaciones arqueológicas. La ausencia de estudios limita nuestro conocimiento sobre la fortaleza medieval tanto en el aspecto material como en su uso e historia. 


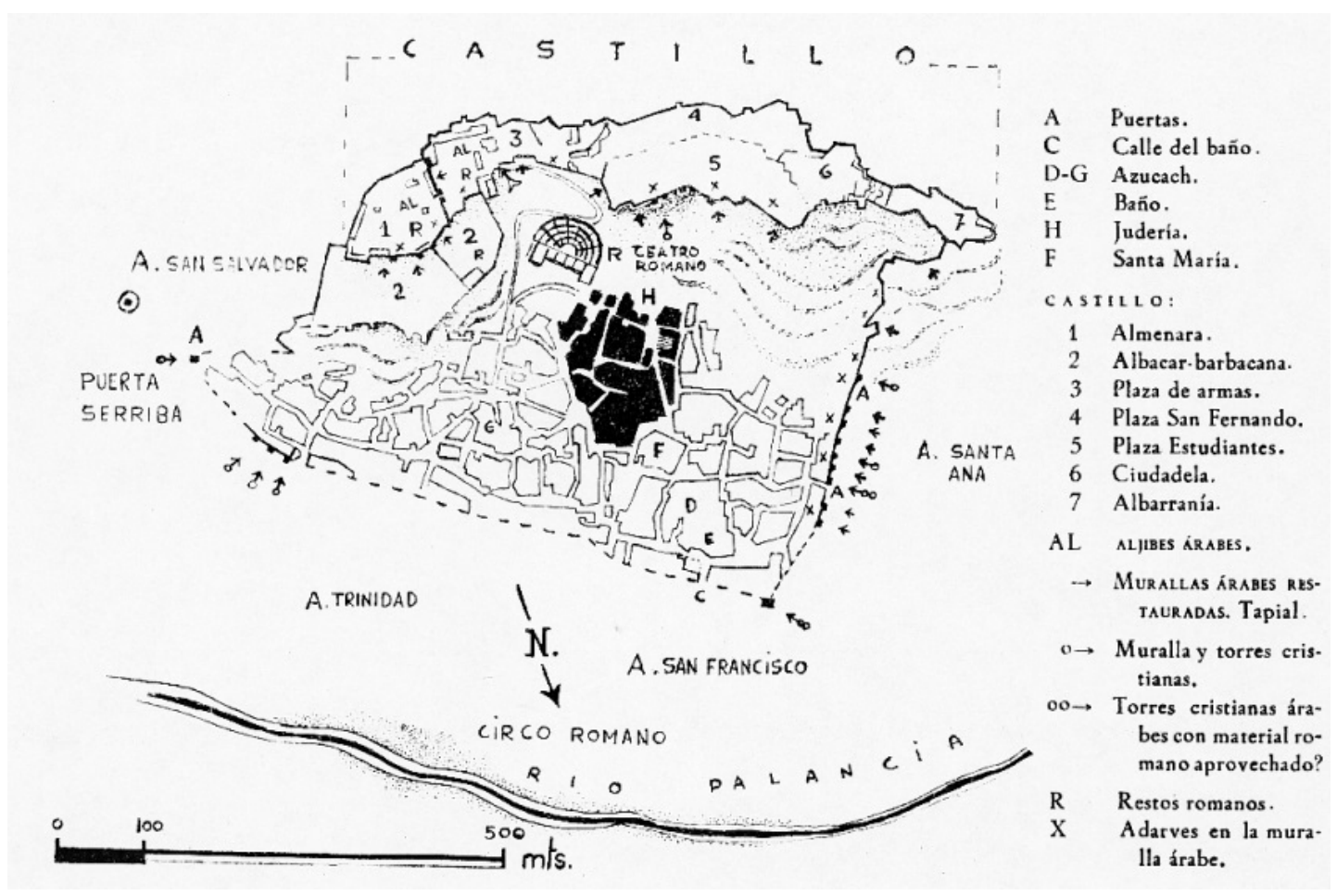

Figura 2. Plano del recinto fortificado de Morvedre realizado por Basilio Pavón (Pavón

Maldonado, 1978: 185).

la frontera castellana del reino de Aragón que describe Mario Lafuente a mediados del siglo XIV y que motivó diferentes campañas de reconstrucción durante la guerra (Lafuente, 2014: 269-344). A esto deberíamos sumar la constante reparación que necesitaban los castillos valencianos, los cuales habían heredado el tradicional sistema andalusí de construcción con tapial, rápido y barato, pero que requería obras de mantenimiento periódicas (García Marsilla, 2003: 7-8).

Es posible que el monarca ya hubiese mandado fortificar y reforzar las estructuras del castillo, de hecho, conservamos algunas de estas órdenes para otros castillos y para otras cronologías marcadas por la conflictividad. Por ejemplo, en unos capítulos de 1377 que se aplicaban a todos los castillos del reino de Valencia se ordenaba la «reparació e obra dels dits castells e forces, així de torres, barbacanes, aljubs...» ${ }^{7}$. Tampoco deberíamos descartar que las obras que se reflejan en el volumen de contabilidad estudiado fuesen, en parte, una continuación de las que habían empezado

\footnotetext{
7 ACA, Real Cancillería, 1464, f. 148v.
}

los castellanos durante su ocupación. De hecho, la misma contabilidad nos habla de «altres obres del palau del Castell lo qual començà lo Rey de Castella» ${ }^{8}$.

El primer paso en este proceso constructivo y de rearme fue la destrucción de los edificios situados fuera de la muralla, concretamente derribaron el campanario y la iglesia de San Salvador, así como algunas casas del arrabal. De la misma forma se desmontaron las bastidas y otras estructuras de asedio que el monarca aragonés había mandado construir para tomar la villa9. Con esto se intentaba arrebatar a los eventuales asaltantes cualquier posibilidad de cobertura, además se conseguía una fuente de suministro de materiales de construcción reciclados. Una estrategia habitual que fue practicada por los aragoneses en otras posiciones como Calatayud o Cella (Lafuente, 2014: 320-326).

El segundo paso fue la construcción y la reparación de muchas de las estructuras defensivas de Morvedre. La contabilidad, por desgracia, no

\footnotetext{
${ }^{8}$ ACA, Mestre Racional, 2433, f. 55r.

${ }_{9}$ Ibid., f. 50r-51v.
} 
nos detalla todas las obras que se realizaron en el castillo, de hecho, en muchas ocasiones, es imposible identificar en qué recinto del edificio están trabajando. En cambio, sí que nos permite saber que el principal trabajo al que se dedicó la mayor parte del tiempo y del personal fue el de tapiado en las murallas y las torres.

Por otra parte, sí tenemos identificada la obra de los carpinteros en la preparación de los ginys o ingenios, maquinaria militar defensiva del castillo. Normalmente, se trataba de las reparaciones de piezas que existían antes de la ocupación castellana, pero también se construyó una nueva. Así mismo, se trabajó en el abastecimiento de piedras, para usarlas tanto de munición como de contrapeso, y en la realización de las plataformas en las que se sustentaban. Otras estructuras defensivas que aparecen identificadas son los carmanchons, galerías cubiertas hechas de madera construidas en la parte superior de los muros para dar una mayor protección a los defensores (Lafuente, 2014: 322-323).

Finalmente, se revisaron todas las estructuras que tenían que servir para albergar a la guarnición: se repararon casas y almacenes, se desescombraron los espacios donde se debían depositar las reservas de alimentos, se limpiaron los aljibes y las canalizaciones del castillo... Al contrario que las obras de la villa, que servían para poner en funcionamiento de nuevo las regalías dañadas por la guerra, las reparaciones y acciones de construcción en la fortaleza servían para preparar el castillo para estar en el que teóricamente debía ser su estado natural. Este hecho nos da una imagen muy potente de cómo estaban las estructuras defensivas valencianas antes de la guerra con Castilla.

A pesar de la mucha información que ofrece el registro es imposible identificar las obras allí descritas en el registro arqueológico. Esto se debe en parte a la ausencia de excavaciones y estudios sobre el castillo en época feudal. Pero también al mismo carácter de esta obra y las demás que se realizaron entre los siglos XIV y XV. Las intervenciones de mantenimiento del tapial y los cambios en el uso de las estructuras del castillo eran tantos que probablemente gran parte del trabajo que se describe en este cuaderno fuese indistinguible pasado un siglo.

\subsection{La mano de Obra}

Una acción reparadora de tal envergadura requería necesariamente de la contratación de centenares de trabajadores. Hemos contabilizado alrededor de 650 individuos empleados en la reparación del castillo de alguna u otra forma. Tal y como podemos apreciar (Fig. 3) la mayor parte de los salarios (8520 sueldos y 4 dineros) se pagaron a aquellos que trabajaban estrictamente en las labores de reparación ya fuesen maestros de obra, tapiadores, picadores, carpinteros o peones. Las obras implicaron también mano de obra femenina garbillando arena y aportando cal, agua y herramientas cuando era necesario. Menor fue el gasto dedicado al transporte (1782 sueldos y 3 dineros) que cubría los gastos del flujo de carreteros y arrieros que abastecían al castillo de viandas, armamento y materiales de construcción. También se emplearon aserradores y herreros que se dedicaron realizar trabajos auxiliares y secundarios en el castillo y en la villa, tales como puertas, tablas, piezas de las armas de asedio, llaves, cerraduras... Finalmente se han incluido otros salarios de trabajos más difíciles de clasificar cómo los notarios o los responsables del mantenimiento de los carros y las bestias. El enorme volumen de gasto que representa esta sección (5308 sueldos y 4 dineros) se agranda si tenemos en cuenta que hemos incluido los 1500 sueldos por el trabajo del propio Francesc de Vic y otros 2100 sueldos de un contrato con Bertomeu Soler, vecino de Morvedre, a quién se subcontrataba para las reparaciones de 5 molinos de la villa.

Los diferentes oficios estaban jerarquizados a través de su jornal tal y como podemos apreciar en la Tabla 1. Así, en la parte más alta de esta pirámide laboral estuvieron los maestros aserradores, que cobraban 4 sueldos y 8 dineros $^{10}$, y Benet Boix, maestro mayor de las tapias, que cobraba 4 sueldos diarios por su trabajo a lo cual se añadía un sueldo semanal para pagar su cama y provisión $^{11}$. En una posición parecida estaban Pere Olomar, Jaume Carbonell o Mateu Escala, maestros carpinteros, que percibían 3 sueldos y la misma provisión que el anterior ${ }^{12}$. En el otro extremo se encontraban los salarios de peones, discípulos y mujeres, marcadamente inferiores. Se trataba de un sistema de estimación del trabajo, no siempre preciso, en el que no solo se valoraba la mano de obra, sino también la especialización y la cualificación laboral. Por otra parte, el pago a los trans-

\footnotetext{
${ }_{10}$ Ibid., f. $96 \mathrm{r}$

11 Ibid., f. $57 \mathrm{v}$

12 Ibid., f. $55 \mathrm{r}$
} 
portistas se realizaba normalmente tomando en consideración otras variables tales como el número de animales que utilizaban, el número de viajes que realizaban o la distancia entre el castillo y el punto de origen.

\begin{tabular}{|c|c|c|}
\hline $\begin{array}{c}\text { Categoría } \\
\text { Socioprofe- } \\
\text { sional }\end{array}$ & Salario diario & $\begin{array}{c}\text { Referencia } \\
\text { documental }\end{array}$ \\
\hline $\begin{array}{c}\text { Maestro ase- } \\
\text { rrador }\end{array}$ & 4 ss. 8 ds. & $\begin{array}{c}\text { ACA, Mestre } \\
\text { Racional, 2433, } \\
\text { f. 96r }\end{array}$ \\
\hline $\begin{array}{c}\text { Maestro de las } \\
\text { tapias }\end{array}$ & 4 ss. & Ibíd., f. 57v \\
\hline $\begin{array}{c}\text { Maestro he- } \\
\text { rrero }\end{array}$ & 4 ss. & Ibíd., f. 100r \\
\hline $\begin{array}{c}\text { Maestro car- } \\
\text { pintero }\end{array}$ & 3 ss. - 2 ss. 6 ds. & Ibíd., f. 55r \\
\hline Mallador & 2 ss 6 ds. - 1 ss. & Ibíd., 100r \\
\hline Picador & 2 ss 6 ds. - 2 ss & Ibíd., f. $58 \mathrm{r}$ \\
\hline Peón & 2 ss. - 1 ss. 6 ds. & Ibíd., f. $58 \mathrm{r}$ \\
\hline Aprendiz & 1 ss. 2 ds. - $1 \mathrm{ss}$. & Ibíd., f. 69r \\
\hline Mujer & 1 ss. & Ibíd., f. 62v \\
\hline
\end{tabular}

Tabla 1. Salarios diarios de las diferentes categorías socioprofesionales que trabajaron en las obras del Castillo de Morvedre.
Durante los diez meses que duró la obra se trabajó sin descanso, especialmente en los primeros meses. En la primera semana de trabajo, en septiembre de 1365, había 77 personas empleadas y esta cifra aumentó hasta un punto máximo de 112 en la última semana de noviembre. Por el contrario, a partir de abril los números descenderán rápidamente desde 45 hasta 12 en la última semana de la que se ocupa el cuaderno de gastos. Da la impresión de que en los primeros momentos las obras se siguieron casi a contrarreloj, con el miedo constante a un ataque castellano. Una pista en este sentido nos la aporta una pequeña noticia escrita en el libro que nos habla de cómo no se respetó la fiesta de san Lucas y se trabajó por motivo del avistamiento de una galera castellana ${ }^{13}$.

La jornada laboral venía marcada por las horas solares, desde el alba al ocaso, de lunes a sábado a mediodía (García Marsilla e Izquierdo Aranda, 2013: 244-245). A parte de los domingos y las fiestas de guardar, lo único que interrumpía el ritmo de trabajo eran las circunstancias meteorológicas. La lluvia paralizó las obras en diversas ocasiones, al menos aquellas que se realizaban al descubierto pues las de herreros y aserradores continuaron ajenas al mal tiempo al trabajar en casas privadas o en porches construidos expresamente para la ocasión. En algún caso extremo algunas lluvias intensas propiciadas por la gota fría llegaron a causar verdaderos problemas, como el

\footnotetext{
13 Ibid., f. $13 \mathrm{r}$
}



Figura 3. Porcentaje de gastos relativos a salarios en las obras del castillo de Morvedre. 
derrumbe de dos hornos de cal que abastecían las $\operatorname{obras}^{14}$.

\subsection{LOS MATERIALES}

Cualquier obra que se realizaba en las villas del reino de Valencia, requería de un constante abastecimiento de materia prima constructiva. Cuanto mayor era la obra, mayor era el número de proveedores implicados. Así pues, una operación como la que nos ocupa precisó de la participación activa no solo de los productores locales, sino también de otros núcleos de la zona de influencia de Morvedre.

Como ya se ha dicho, la principal técnica constructiva presente en el castillo de Sagunto era el tapial. Se trataba de un sistema constructivo caracterizado por el uso de moldes o encofrados, llamados tapia, para levantar muros de tierra. Además, la arena se combinaba con cal para aumentar la resistencia del material ${ }^{15}$. Es aquí donde debemos reflexionar sobre el reducido coste que suponía levantar muros de esta manera, solo se necesitaba agua, arena y cal. Los primeros dos elementos eran gratuitos y solo se requería pagar por su transporte, tal y como se demuestra en el pago de jornales a arrieros por subir arena y a peones por transportar agua para hacer las mezclas. En el caso de la arena además había que cribarla, puesto que no solían tomarse en consideración su calidad y era preferible aprovisionarse lo más cerca posible de donde se hacían las obras (García Marsilla e Izquierdo Aranda, 2013: 161-170).

Por el contrario, el abastecimiento de cal sí que generaba un gasto importante porque se trataba de un producto que requería de una elaboración previa. La producción de cal está documentada en el territorio valenciano desde la Edad Media hasta el siglo XX. Se trataba de un negocio lucrativo en los espacios rurales que rodeaban los principales centros demográficos del país. El procedimiento de fabricación pasaba por la selección de piedras calizas para convertir el carbonato de calcio en óxido de cal, para ello se precisaba de hornos que pudiesen calentarse hasta los 800 o $900{ }^{\circ} \mathrm{C}$. Los hornos solían construirse en las montañas, lejos de los núcleos de población y cerca de los bosques

\footnotetext{
14 Ibid., f. 40r.

${ }^{15}$ Sobre la construcción con tapial consultar Font e Hidalgo, 2009.
}

que les servían de combustible (García Marsilla e Izquierdo Aranda, 2013: 148-149).

El mercado de la cal que analizaron García Marsilla e Izquierdo Aranda para la ciudad de Valencia se reproduce a pequeña escala en el área de influencia de Morvedre. Hemos contabilizado al menos trece proveedores, mudéjares en su mayoría, de cal en las obras, sumando un total de 170 almudines de cal, procedentes de cuatro localidades diferentes: Albalat dels Tarongers, Almenara, Beselga y de la misma villa (Fig. 5). Los precios se mantienen estables en 10 sueldos el almudín en el ámbito inmediato del centro constructivo, no obstante, tenemos el caso de Beselga, más alejado, donde el precio oscilaba entre 8 y 9 sueldos $^{16}$. Estas cifras son menores que aquellas de la ciudad de Valencia que en la misma cronología rondan los 21 sueldos el almudín. Además, según parece se mantendrán estables para el ámbito de Sagunto hasta mediados del siglo XV, cuando aumentará hasta los 15 sueldos (García Marsilla e Izquierdo Aranda, 2013: 157-158).

Otro material abundante es el cerámico, en forma de ladrillos y tejas. Al contrario que en la icónica arquitectura mudéjar aragonesa, el ladrillo nunca fue un elemento central en las fábricas valencianas, y mucho menos en los castillos. Es por eso que solo hemos localizado una compra de 1125 ladrillos por 28 sueldos a la viuda de un proveedor local ${ }^{17}$. Su uso solo está documentado en el castillo en los porches bajo los que trabajaban algunos artesanos y en algunos detalles de las casas del interior de la fortaleza. Todo lo contrario, puede decirse de las tejas necesarias para cubrir muchas estructuras del castillo y la villa, ya fuesen casas, almacenes, molinos, baños... Fueron necesarias 15 compras, sumando un total de 21 250 tejas adquiridas a precio fijo de 25 sueldos el millar, para abastecer la enorme demanda de las obras. Predominan los proveedores locales y solo dos son de puntos vecinos: Canet y una población que no hemos podido identificar llamada Alquería Blanca $^{18}$.

El estudio sobre el abastecimiento de madera es más complicado pues muchas de las compras ya habían sido procesadas en tablones o en bigas. La mayor parte de las compras de madera se realizaron en Morvedre y en Valencia, pero desco-

\footnotetext{
16 ACA, Mestre Racional, 2433, f. 122r-129v

17 Ibid., f. $115 \mathrm{v}$

18 Ibid., f. $114 \mathrm{v}$
} 
nocemos de dónde provenía la materia prima. A pesar de esto, conservamos algunos asientos relativos al cortado de madera de olmo, morera, olivo, aligonero, pino... todo proveniente de la huerta de Morvedre. Finalmente, y de manera residual, se compraron para detalles determinados pequeñas cantidades de yeso, cañas, hierro, pega, cera, sebo...

Es interesante señalar cómo no solo se compraron materiales nuevos, sino que también se recurrió a la reutilización de materiales reciclados provenientes de casas derribadas o edificios dañados, especialmente de los arrabales que el mismo rey había mandado destruir. De entre los escombros de las estructuras se tomaron tejas, ladrillos, vigas de madera y carbón para su uso en las reparaciones.

Cabe destacar que la apremiante demanda de mano de obra que comentábamos en el apartado anterior tiene su reflejo también en el abastecimiento de materiales. Tenemos noticias que apuntan hacia un control bastante rígido sobre la materia prima que pretendía garantizar el abastecimiento del castillo a toda costa. Así, por ejemplo, sabemos que se hizo un bando público que anunciaba que todo el carbón que se hiciese en la villa debía destinarse a las obras bajo pena de sanción económica y pérdida del mismo ${ }^{19}$. Esto sería extrapolable a otros materiales como la madera. De hecho, se conservan pagos a individuos por delatar a vecinos que la ocultaban en sus casas, probablemente con la intención de reparar los desperfectos que los meses de asedio habían causado en sus viviendas. Un caso paradigmático es el de un tal Domingo que recibía 4 sueldos el 22 de diciembre por señalar a un tejedor que ocultaba tablas en su casa ${ }^{20}$.

\section{EL APROVISIONAMIENTO DEL CASTILLO}

Reparar los muros y fortificar la villa era solo una de las tareas asignadas a Francesc de Vic para con el castillo. Otra parte fundamental de esta operación era el abastecimiento de provisiones en el castillo. En la mayor parte de los casos, el éxito de los asedios medievales residió en la capacidad de los defensores de sobrevivir largos períodos de

\footnotetext{
${ }^{19}$ Ibid., f. 12v.

${ }^{20}$ Ibid., f. $33 \mathrm{v}$.
}

tiempo sin una fuente estable de comida y agua. De hecho, en pocos casos los asaltantes consideraron el ataque directo como la mejor opción. Por eso, la tarea de los alcaides o castellanos era, especialmente en tiempo de guerra, la de garantizar la presencia de suministros en las bodegas ${ }^{21}$.

En el caso que nos atañe, las tropas de Pedro el Ceremonioso se encontraron con unas despensas casi vacías, fruto de un asedio de varios meses que había forzado a la guarnición castellana a la rendición. Por eso, la contabilidad nos ofrece un detallado informe de las compras de víveres realizadas por los nuevos ocupantes del castillo. A pesar del valor cualitativo de los datos que nos ofrece este registro contable, la suma de las cantidades compradas es en algunos casos inferior al volumen total de alimentos que se encontraban en las despensas del castillo según se desprende del inventario realizado al final de las obras, hecho que nos hace pensar en que parte de los gastos derivados del abastecimiento de la fortaleza recayeron en varios funcionarios y administraciones, y no solo en Francesc de Vic.

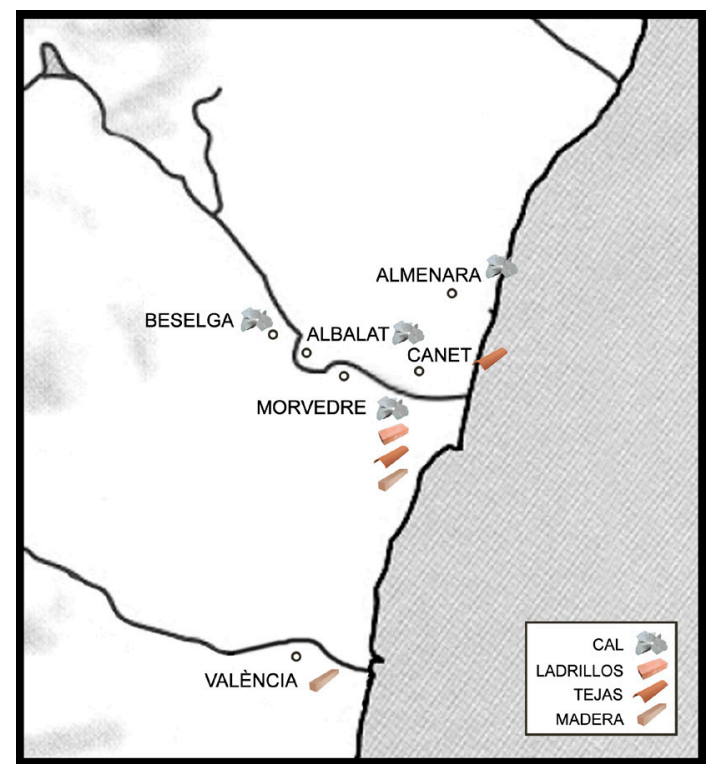

Figura 4. Distribución geográfica de los centros de abastecimiento de materiales constructivos.

${ }^{21}$ Prueba de esta voluntad de abastecimiento alimenticio la vemos también en las políticas que tomó la ciudad de Valencia para mantener abierta la llegada de víveres durante la guerra con Castilla. Se ha estudiado el abastecimiento de la capital valenciana durante la guerra en Sanahuja Ferrer, 2017. 
En cualquier caso, las compras realizadas entre septiembre de 1365 y mayo de 1366 no pretendían alimentar diariamente a las guarniciones que se estableciesen en el castillo durante el conflicto, sino más bien pretendía ser una reserva para la tropa estacionada en caso de sitio prolongado. Por eso encontramos poca variedad de alimentos, pero en grandes cantidades. Lo que más abundaba era el cereal, mayormente en forma de trigo. Este era el elemento central de la alimentación medieval en casi todo el continente europeo, por eso las extensiones de cereales dominaban el paisaje agrícola peninsular en el siglo XIV. No obstante, el trigo transportado y almacenado en Morvedre no se dedicó a la elaboración de pan, sino a la de bescuyt, tal y como se indica en los pagos correspondientes del documento. Se trataba de una especie de bizcocho o galleta que se obtenía cociendo dos veces la pasta poco fermentada que se utilizaba especialmente para el avituallamiento de naves y tropas. El producto final podía almacenarse durante largos períodos de tiempo, de hecho, en el inventario que se realizó el 5 de julio de 1366 aún se registraba la presencia importante de bescuyt castellano que había estado almacenado desde, al menos, hacía diez meses ${ }^{22}$.

En este mismo inventario figuraban 360 quintales, 2 arrobas y 10 libras de este bizcocho, es decir, 18430 kilogramos de bescuyt. Según las ordenaciones de 1354 escritas por Bernat Cabrera, capitán general de la armada del rey Pedro el Ceremonioso, en las naves reales se debía administrar una ración diaria a los marineros de dos libras (710 gramos) de galleta (Capmany, 1787: 101). De acuerdo con estos datos podemos calcular que una guarnición de 92 hombres, como aquella que se instaló en la plaza después de su recuperación en septiembre de 1365 , podría mantenerse a base de este alimento unos 280 días. A esto cabe añadir 103 cahices (20 703 litros) de trigo que aún no habían sido panificados y 425 cahices $(85425)$ de arroz, cereal que iba aumentando en importancia en la alimentación medieval de la población del reino de Valencia. En menor medida se almacenó carne salada de cerdo para complementar la alimentación de los eventuales defensores, en total unas 1035 libras (367,5 kilogramos). También había una pequeña reserva de aceite de 73 arrobas $(871 \text { litros })^{23}$.

\footnotetext{
22 ACA, Mestre Racional, 2433, f. 34v.
}

${ }_{23}$ Ibid., f. $143 \mathrm{v}-145 \mathrm{v}$.

\section{EL ARMAMENTO}

El último apartado que analizaremos será el de las compras de material bélico que se usaría para defender la posición en caso de un nuevo asalto castellano. Este apartado ocupaba un modesto $17 \%$ del presupuesto de las obras, no obstante, cabe destacar que gran parte del gasto en armamento no dependía directamente del monarca y que también intervenían otras entidades, así como individuos particulares. Para entender mejor este aspecto cabe diferenciar dos grandes tipos de gastos militares: el armamento personal y los ingenios defensivos.

Sin duda, la construcción de las piezas de artillería resulta uno de los aspectos más significativos de todo el documento. A su entrada en la villa los aragoneses inventariaron 18 trabucos entre grandes y pequeños, de los cuales dejaron 9 en la villa y subieron 9 al castillo ${ }^{24}$. Durante los diez meses que duraron las obras se nos anotan muchas entradas referidas a carpinteros que se dedicaron a reparar los ingenios y construir sus bases, compras de cuerdas y grasas animales para mejorar su funcionamiento o pagos a transportistas que subieron piedras de la rambla para usarse como munición y como contrapeso de las máquinas.

El inventario final, nos permite ver como en julio de 1366 se habían distribuido 9 trabucos plenamente operativos en las murallas de la villa y 10 en el castillo, hecho que nos muestra que se construyó una pieza nueva durante las obras ${ }^{25}$. También aparecen recogidas piezas sueltas de fundíbulo que se almacenaron como repuesto o con la perspectiva de fabricar nuevas armas. Lamentablemente, la documentación no nos permite calcular el tiempo de fabricación o el precio que alcanzaban estas máquinas. Sí que deducimos que se colocaron en puntos clave de la fortaleza siguiendo un pensamiento estratégico que se nos escapa. Así, por ejemplo, el "giny de Sant Antoni" (pues cabe destacar que todas estas armas estaban bautizadas), se situaba en la albacara, es decir, en la parte inferior del castillo que daba acceso a la villa.

De igual forma, desconocemos a qué categoría de máquina de guerra pertenecía cada pieza identificada "giny" o ingenio. Todas funcionaban por el sistema de contrapeso fijo consistente en una caja rellena con diversos tipos de materiales, que al descender por su propio peso desplazaba la

\footnotetext{
${ }^{24}$ Ibid., f. 5r.

25 Ibid., f. 140v-144r.
} 
viga central en cuyo extremo se situaba la "fona" u honda que contenía el proyectil. La diferencia en la terminología identificativa viene marcada muchas veces por el número de contrapesos o su distribución en el arma (Cantos Carnicer, 2016: 149-150). Cabe destacar una última pieza que se situaba entre las dos categorías de armamento que dibujábamos al inicio del apartado: una ballesta de torno. Se trataba de una ballesta de mayor tamaño y precio, costaba 50 sueldos respecto a los 27 que costaban las normales, que se emplazaba en una posición fija y se accionaba por un sistema fijo de torsión que le daba un mayor impulso respecto a aquellas accionadas manualmente o con sistemas más primitivos.

Por lo que respecta al equipamiento personal, conservamos un gran número de apocas relativas a la compra de armamento defensivo y ofensivo, así como el registro de todas las armas encontradas e inventariadas en el castillo cuando se terminaron las operaciones de reconstrucción y reabastecimiento. Se compraron un total de 500 lanzas, 1200 dardos, 79 ballestas, 20000 saetas, 100 paveses, 50 arneses (formados por coraza, gorguera y capelina), 38 capelinas y 30 gorgueras. Las compras se realizaron directamente a los productores o se pagaron a otros funcionarios reales. Además, se primaron las compras a productores de la capital valenciana, con la excepción de las ballestas que se adquirieron de un ballestero de Tortosa. Los gastos en armamento no se limitaban únicamente a la compra de material, sino también a su reparación y puesta a punto. Se compraron clavos y telas para cubrir las armaduras, y se contrataron dos armeros para reparar unas 50 armaduras recogidas del castillo. También se contrataron pintores, para pintar las armas reales de Aragón sobre los escudos; armeros, que afilaron y montaron las lanzas y los dardos; y ballesteros, para colocar y tensar las cuerdas de las ballestas ${ }^{26}$.

Cabría preguntarse quién era el destinatario de todo este armamento. La Corona de Aragón en el siglo XIV carecía, como la mayor parte de los estados feudales del momento de un ejército permanente financiado con los ingresos de tributos e impuestos. Las huestes del reino solo se convocaban en coyunturas determinadas para las que se requería un esfuerzo fiscal enorme, tan grande que la mayor parte de los especialistas coinciden en señalar las guerras de la Baja Edad Media como uno de los

\footnotetext{
${ }^{26}$ Ibid., f. 122r-136v.
}

principales factores en el nacimiento de los estados modernos con sus nuevos sistemas de tributación. No obstante, los reinos feudales daban pasos continuos hacia las formas de los ejércitos modernos que se consolidaran ya en el siglo XVI. En primer lugar, el papel inequívocamente protagonista de la poderosa caballería feudal empezaba a matizarse. En palabras del mismo Pedro el Ceremonioso:

Experiència, qui és maestre de totes coses, clarament demostra que 1 senyor Rey ne les sues gents no deuen seguir les vestigies de lurs predecessors en los fets de les armes, car ells se armaven es combatien a cavall e ara veu hom que $\cdot 1$ s homens quis armen a la guisa es combaten a peu vencen les batalles als homens a cavall i conquisten regnes e terres e en altra manera son pus forts e pus greus devenhir que nolos de de (sic) cavall ${ }^{27}$.

Este fragmento encabezaba unas ordenanzas en las cuales el rey fijaba unas responsabilidades militares de acuerdo con su nivel económico, expresadas a través del equipamiento que debía poseer cada individuo de acuerdo con su patrimonio. Así pues, según todas las fuentes, el mayor gasto en armamento personal recaía no en los gestores económicos de la monarquía o cualquier otra entidad feudal, sino en el vecino y el ciudadano. La infantería, uno de los motores de la revolución militar bajomedieval, entraba en el tablero bélico, pero a sus expensas ${ }^{28}$.

Las autoridades, tanto en su expresión real, como nobiliaria o municipal, se encargaban de incentivar la posesión de armamento con medidas directas, tales como prohibir la entrada a los cargos de gobierno municipales a aquellos que no pudiesen equiparse con arnés completo de caba-

\footnotetext{
${ }^{27}$ ACA, Cancelleria, registres 1529-1 54r.

${ }^{28}$ El papel de la infantería en la Baja Edad Media ha sido uno de los principales temas de debate en la historiografía militar medieval desde hace décadas. No obstante, la importancia de la infantería ha sido ampliamente confirmada en la Guerra de los dos Pedros en los estudios del doctor Mario Lafuente. Según este autor los almogávares, fletxers, ballesters o llancers, todos de origen no aristocrático, fueron unidades muy utilizadas durante la guerra y demostraron ser muy funcionales en este conflicto caracterizado por acciones de desgaste y asedio (Lafuente Gómez, 2013: 139-144). Aun así, la caballería siguió conformando el núcleo de los ejércitos feudales en la Corona de Aragón hasta el final de la Edad Media, tal y como indica el doctor Jorge Saiz Serrano (2008).
} 
llería $^{29}$ o a través de la las muestras ${ }^{30}$, exámenes de los arsenales personales de una población con el objetivo de identificar, y multar, a quienes no reunían el armamento que les correspondía de acuerdo a su capacidad adquisitiva. Así como acciones indirectas, que incluían, por ejemplo, la protección del armamento delante de los embargos por deudas y empeños ${ }^{31}$. No solo esto, sino que además se intentaba fomentar el buen manejo de las armas a través de la convocatoria de competiciones de ballesta, esgrima o torneos.

Sin duda, hemos de suponer que el equipo de aquellas guarniciones que se apostaron en el castillo de Morvedre cumpliría las demandas que las muestras requerían, ya que el equipo que presentasen marcaría su posterior remuneración ${ }^{32}$. ¿Pero qué hay del resto de la población de la villa sobre la cual recaería en caso de asedio la defensa última de la posición? A pesar de no tener un registro de armamento de la población tenemos otras formas de imaginar cuál era la situación de sus arsenales privados. A partir de un registro notarial extraordinario ${ }^{33}$ de 1348 que conserva 75 inventarios post mortem de vecinos de Sagunt en el momento posterior a la llegada de la peste, observamos que, de los 68 inventarios masculinos, un $85 \%$ tienen alguna pieza de armamento. La distribución es desigual, pues por una parte solo 11 de ellos tienen un arma o 24 tienen entre 2 y 4 , por otra parte 7 individuos tienen más de 14. Entre todos reunían 48 espadas, 55 cuchillos y puñales, 140 lanzas, 37 ballestas y 56 piezas defensivas tales como cascos, escudos o corazas. Aunque cabe pensar que no solo el número es importante y que también se debe considerar su estado. Muchas de

${ }^{29}$ ARV, Reial Cancillería, 286, f. 154r-155v. Se trata de una ordenación posterior, realizada en 1462, en el contexto de la Guerra Civil Catalana, pero es significativa del pensamiento real con respecto a la responsabilidad de la ciudadanía de defender el reino.

${ }^{30}$ No hemos encontrado ningún registro de muestras de combatientes en el reino de Valencia en la cronología medieval, pero sí que conservamos algunos para el reino de Mallorca tal y como se recoge en Alomar, 1995: 99-100. También conservamos otro ejemplo de entre 1380 y 1390 para Barcelona recogida en Reche Ontillera, 2015.

${ }^{31}$ Furs de València, Llibre VIII, Rúbrica VIII, De donacions; Llibre I, Rúbrica IV, Del quart e de les penes de la cort.; Llibre VIII, Rúbrica II, De penyores. Colom, G. y García, A. (1970-2007): Furs de València, Barcelona, Barcino: Fundació Jaume I.

${ }^{32}$ Los lanceros de la guarnición cobraban unos 1,5 sueldos por día, mientras que los ballesteros cobraban 2 .

${ }^{33}$ AMV, Fuentes Notariales, I-1, Domingo Joan. ellas aparecen descritas con adjetivos tales como viejo, sutil, corroído... Imagen que nos vincula con el fragmento de la obra «la Brama dels Llauradors» de Jaume Gassull en el que se nos describe de manera satírica el armamento de una masa de campesinos alborotados. En ella se nos mencionan lanzas tan viejas que huelen a podrido, espadas tan oxidadas que no se pueden desenvainar, armaduras que se rompen al doblarse... ${ }^{34}$

Los inventarios tampoco son una fuente infalible para estudiar el armamento medieval, pues nos ofrece una imagen fija que no tiene en cuenta que muchos vecinos podían reparar o renovar su arsenal ante la proximidad de un conflicto. Pero, en cualquier caso, podemos pensar que las compras de material bélico por parte de la monarquía, tales como las que se muestran en el cuaderno de contabilidad analizado, tenían el objetivo de armar, parcial o totalmente, a aquellos incapaces de reunir el equipo óptimo para participar, en este caso, en la defensa de Morvedre.

Es muy difícil individuar el equipo que utilizaba la infantería feudal, tanto de lanceros como de ballesteros. El equipo de los lanceros se formaba por varias lanzas, unos dardos, una espada y un cuchillo. Su equipo defensivo se caracterizaba por un pavés y varias piezas de armadura la calidad de las cuales dependía de su capacidad adquisitiva. El equipo de los ballesteros era similar solo que incluía además 1 o 2 ballestas y unos 100 o 200 proyectiles (Orsi Lázaro, 2009: 194-195).

A partir de estos datos, $y$ teniendo un conjunto muy amplio de precios de armas y de salarios contemporáneos proponemos un ejercicio en el que relacionemos el precio de cada pieza de armamento con el tiempo que un trabajador medieval, de acuerdo con su salario, tardaría en poder adquirirlo (Tab. 2); así como el tiempo de trabajo que se debería invertir para conseguir un equipo completo. El resultado nos muestra el enorme esfuerzo económico que debería afrontar un individuo para adquirir los pertrechos bélicos necesarios para participar en una guerra. Con esto, no obstante, estamos olvidando la enorme importancia que tenía el mercado de segunda mano en la obtención de manufacturas a un precio más asequible ${ }^{35}$. Así

${ }^{34}$ Obra consultada en la edición Rodríguez-Puertolas y Alpera, 1973: 198-199.

${ }^{35}$ De la base de datos que elabora Juan Vicente García Marsilla sobre los 8000 objetos vendidos en subastas públicas en València entre los siglos XIV y XVI, 420 de ellos, es decir el 5,25\%, son armas, acumulando un valor total de 4313 sueldos. Garcia Marsilla et alii, 2015: 306. 


\begin{tabular}{|c|c|c|c|c|}
\hline & $\begin{array}{l}\text { Salario de Maestro artesa- } \\
\text { no y de la construcción }\end{array}$ & Salario Agrícola & $\begin{array}{l}\text { Salario de un peón artesa- } \\
\text { no o de la construcción }\end{array}$ \\
\hline & & $2,5-4,5$ sueldos & $2,5-3$ sueldos $^{36}$ & $1,5-2,5$ sueldos \\
\hline Lanza & $2-4,5$ & $<1-2$ & $1-2$ & 2 \\
\hline Dardo & 1 & $<1$ & $<1$ & $<1$ \\
\hline Ballesta & 24,5 & $5-9$ & $8-9$ & $9-16$ \\
\hline Pavés & $8-10$ & $1-4$ & $2-4$ & $3-6$ \\
\hline Saetas & $4^{37}$ & $<1-2$ & 2 & $2-3$ \\
\hline Arnés ${ }^{38}$ & $33-45$ & $7-18$ & $11-18$ & $18-30$ \\
\hline $\begin{array}{l}\text { Equipo de } \\
\text { lancero }^{39}\end{array}$ & $45-64$ & $10-26$ & $15-26$ & $26-43$ \\
\hline $\begin{array}{l}\text { Equipo de } \\
\text { ballestero }^{40}\end{array}$ & $74,5-113$ & $16-46$ & $24-46$ & $46-76$ \\
\hline
\end{tabular}

Tabla 2. Relación del esfuerzo económico de la compra de armamento de acuerdo con los días de trabajo necesarios para adquirir una pieza.

como la capacidad de mantenimiento y reparación de material antiguo por una fracción del precio de compra en el mercado de primera mano. En cualquier caso, la inversión necesaria para obtener este equipo condicionaba en gran medida a un gran porcentaje de la población que, al no dedicarse profesionalmente a la guerra, dependería de las compras institucionales de armamento para defender su comunidad local y su reino.

\section{CONCLUSIÓN}

La contabilidad de las obras de reconstrucción y abastecimiento del castillo de Morvedre nos permiten sacar dos conclusiones tajantes. En primer lugar, la importancia de la industria de la guerra en la economía valenciana. La construcción y reparación de estructuras defensivas movía anualmente miles de sueldos destinados a la compra de materiales y al pago de soldadas, generando un mercado de productos, una generalización de industrias y una mano de obra de gran vitalidad y dinamismo. Además, las técnicas constructivas valencianas basadas en el uso del tapial requerían de actuaciones anuales sobre la gran mayoría de los castillos y murallas del reino, avivando aún más todas estas demandas. Por su parte, las grandes compras de armamento que vemos plasmadas en nuestra documentación nos hablan de una corporación de armeros con recursos suficientes para una producción sostenida de material bélico ${ }^{36}$. Estamos hablando de unas dinámicas productivas importantes que consolidaran a Valencia como un centro de producción y distribución de armamento en el ámbito regional e internacional.

En segundo lugar, el desinterés que generaba el gasto bélico en el reino en los tiempos de paz. A partir de la conquista, los castillos que no se situaban en las fronteras perdieron rápidamente importancia estratégica y consecuentemente empezaron a decaer. Por una parte, muchos de los hisn andalusís fueron abandonados poco después de la llegada de los feudales. Otros, fueron abandonados décadas después dada la escasa importancia que sus señores les otorgaban. El resto necesitaban reparaciones anuales para paliar el deterioro y solo se realizaron obras importantes en momentos prebélicos. De la misma forma, las fortalezas reales nunca lograron mantener las guarniciones, los víveres y el arma-

36 Pongamos por ejemplo la primera compra de arneses que se refleja en la contabilidad. Las 29 piezas de armadura llegaron al castillo el 6 de octubre. Teniendo en cuenta que la orden de fabricación se realizó alrededor del 15 de septiembre, significa que el armero anónimo responsable de la dicha obra tardó 20 días en fabricarlas, o por el contrario tenía unas existencias considerables para abastecer las demandas militares del monarca. En cualquier caso, nos da una imagen sobre la productividad del oficio y su capacidad para abastecer una demanda inusualmente alta. 
mento que el rey fijaba ${ }^{37}$. Circunstancias que se agudizaban aún más cuando la fortaleza dependía de un señor feudal y no del monarca. La situación era tan precaria que llegaba a suceder incluso en los castillos que guardaban la decisiva frontera del sur (Ferrer i Mallol, 1990: 177-189).

La falta de preparación para la guerra se reproducía en el ámbito privado donde las autoridades presionaban para fomentar la posesión de armas entre la población, siempre con la vista puesta hacia un posible conflicto. Un objetivo muy difícil, especialmente entre las clases más modestas que no consideraban la mejora de sus arsenales personales como una prioridad en su economía familiar. Esto forzaba a las autoridades a invertir en la compra de material para paliar estas deficiencias en el armamento de los que debían ser su última línea de defensa. Todo esto se conjugaba con el gasto en soldadas y los intereses de la deuda pública emitida por la monarquía aumentando el esfuerzo económico de los reyes aragoneses en todos los conflictos bajomedievales, forzándolos a crear nuevos instrumentos de fiscalidad que les permitiesen financiar sus campañas.

\section{BIBLIOGRAFÍA}

Alomar, A. I. (1995): L'armament i la defensa a la Mallorca medieval. Palma de Mallorca, Institut d'Estudis Baleàrics.

Belenguer, E. (2015): Vida y reinado de Pedro IV el Ceremonioso (1319-1387). Lleida, Milenio.

Cantos Carnicer, A. (2016): «Los castillos Mayor y Real de la ciudad de Calatayud en el año 1371 a la luz de dos inventarios del Archivo Real». Gladius, 36: 141-160. https://doi.org/10.3989/ gladius.2016.0007

Capmany, A. de (1787): Ordenanzas de las armadas navales de la Corona de Aragón, aprobadas por el rey Pedro IV año de MCCCLIV. Madrid, Imprenta Real.

Colom, G. y García, A. (1970-2007): Furs de València, Barcelona, Barcino: Fundació Jaume I.

${ }^{37}$ El caso de Sagunto es de nuevo paradigmático, durante el siglo XIV y XV, las cuentas de la bailía reflejan una guarnición pequeña, de entre 6 y 8 hombres, que actuaban en ocasiones cómo meros vigías de la costa e incluso eran empleados durante las obras de reparación (Silvestre Romero, 2004: 143). Esta contabilidad también recoge pocas compras de víveres y armamento, y muy concentradas en tiempos de guerra e inestabilidad. Por su parte, se produjeron una decena de actuaciones y reparaciones en el castillo durante el siglo XV que generalmente pretendían un mantenimiento de las estructuras (Diaz Borrás, 1998-1999).
Díaz Borrás, A. (1998-1999): «Las obras de conservación del Castillo de Sagunto a lo largo del siglo XV». Arse: Boletín anual del Centro Arqueológico Saguntino, 32-33: 125-154.

Ferrer i Mallol, M. T. (1990): Organització i defensa d'un territorio fronterer, La Governació d'Oriola en el segle XIV. Barcelona, CSIC.

Font, F. e Hidalgo, P. (2009): Arquitectura de tapia. Castelló, Colegio Oficial de Arquitectos Técnicos de Castellón.

Furió, A. (2001): Història del País Valencià. València, 3 i 4.

García Marsilla, J. V. (2003): «Las obras que nunca se acaban. El mantenimiento de los castillos en la Valencia Medieval: Sus protagonistas y sus materiales». Ars Longa, 12: 7-15.

García Marsilla, J. V. e Izquierdo Aranda, T. (2013): Abastecer la obra gótica: El mercado de materiales de construcción y la ordenación del territorio en la Valencia bajomedieval. València, Generalitat Valenciana: Conselleria d'Infraestructura Territorio i Medi Ambient.

García Marsilla, J. V.; Navarro Espinach, G. y Vela Aulesa, C. (2015): «Pledges and Auctions: the Second-hand Market in the Late Medieval crown of Aragon», Il comercio al minuto. Domanda e oferta tra economía formale e informale secc. XIII-XVIII, Atti 46 delle "Settimane di Studi" e altri Convegni. Florencia, Firenze University Press: 295-317

Lafuente Gómez, M. (2012): Un reino en armas: la guerra de los Dos Pedros en Aragón (1356-1366). Zaragoza, Institución Fernando el Católico.

Lafuente Gómez, M. (2013): «Categorías de combatientes y su armamento en el Aragón Bajomedieval: La Guerra de los Dos Pedros». Gladius, 33: 131156. https://doi.org/10.3989/gladius.2013.0006

Lafuente Gómez, M. (2014): Dos Coronas en guerra: Aragón y Castilla (1356-1366). Zaragoza, Servicio de Publicaciones de la Universidad de Zaragoza.

Orsi Lázaro, M. (2008): «Vaguerosos e malandrins y ballesters bons e bé atreçats. Notas sobre la infantería de Pedro el Ceremonioso en una armada real a Cerdeña (1354)», Actas del IV Simposio internacional de Jóvenes Medievalistas. Murcia, Servicio de Publicaciones, Ayuntamiento de Lorca: 187-202.

Pavón Maldonado, B. (1978): «Sagunto: Villa medieval de raíz islámica». Al-Andalus: revista de las Escuelas de Estudios Árabes de Madrid y Granada, 43: 181-199.

Reche Ontillera, A. (2015): «El censo militar de Barcelona de 1389-1390 y la autodefensa urbana». Roda da Fortuna, 4: 98-114.

Rodríguez-Puértolas, J. y Alpera, LL. (1973): Poesia i societat a l'edat mitjana. Palma de Mallorca, Moll.

Saiz Serrano, J. (2008): Caballeros del rey: nobleza y guerra en el reinado de Alfonso el Magnánimo. València, Publicacions de la Universitat de València.

Sanahuja Ferrer, P. (2017): «Con el hambre a las puertas. El abastecimiento de Valencia durante la Guerra de los Dos Pedros (1356-1366)». Medievalismo: Boletín de la Sociedad Española de Estudios 
Medievales, 27: 327-351. https://doi.org/10.6018/ medievalismo.27.310691

Silvestre Romero, A. (2004): Els llibres de comptes de la batllia de Morvedre a la fi del segle XIV. València, Publicacions de la Universitat de València.
Soldevila, F. (2014): Crònica de Pere III el Cerimoniós. Barcelona, Institut d'Estudis Catalans.

Viciano Navarro, P. (2013): Els peus que calciguen la terra: llauradors del País Valencià a la fi de l'edat mitjana, València, Publicacions de la Universitat de València.

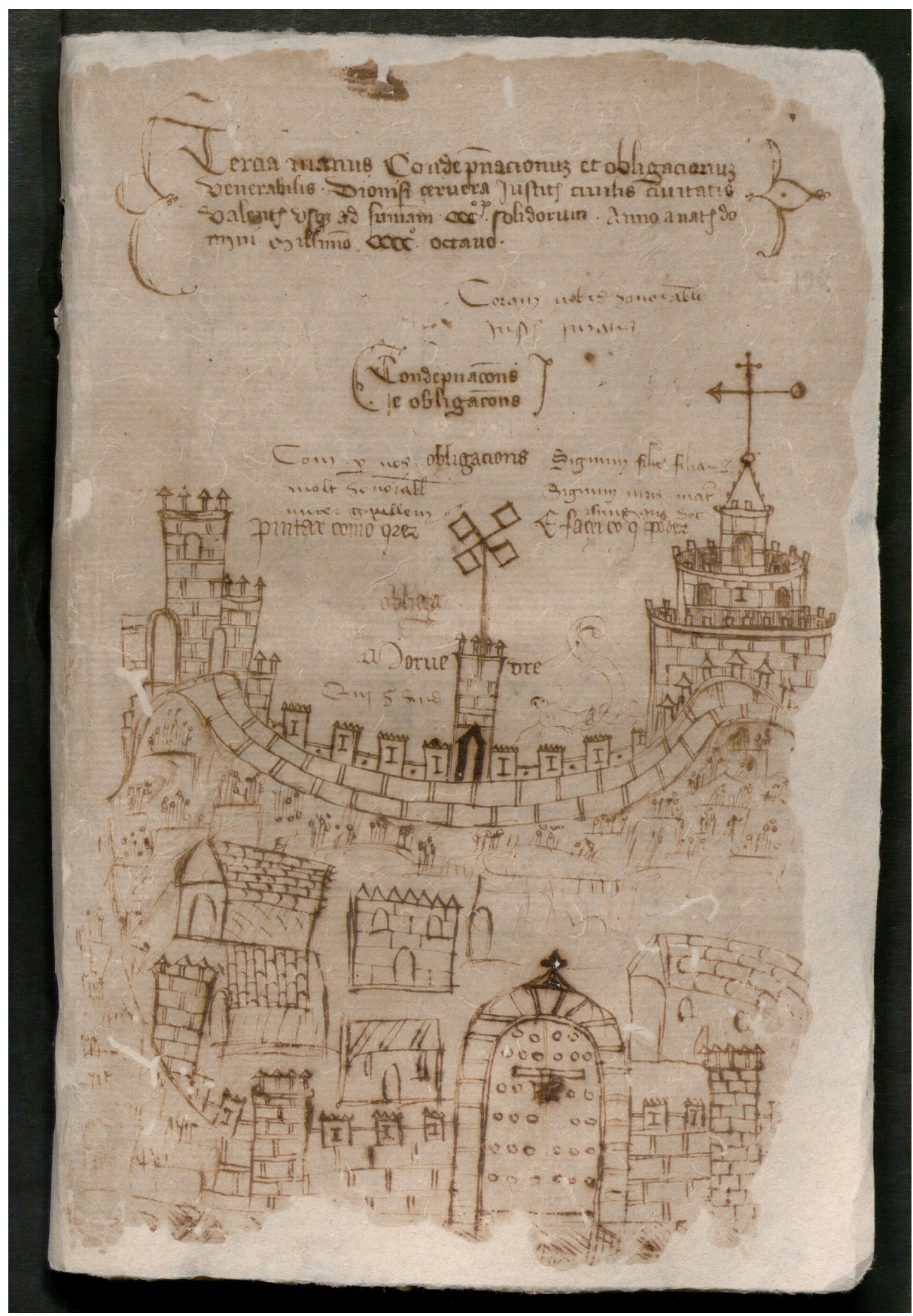

Figura 5. Dibujo del Castillo de Sagunto en 1408 extraído de un libro del Justícia de 300 sueldos (ARV, Justícia 300 sous, Condemnacions i obligacions $30,1408,3^{\text {a }}$ mano, portada). 
